EPJ Web of Conferences 24, 05007 (2012)

DOI: $10.1051 /$ epjconf/20122405007

(C) Owned by the authors, published by EDP Sciences - SIF, 2012

\title{
Insights on radon survey at the Stromboli volcano
}

\author{
M. Laiolo ${ }^{1}$, C. Cigolini ${ }^{1}$, D. Coppola ${ }^{1}$ and G. Gervino ${ }^{2}$ \\ ${ }^{1}$ DSMP, Università di Torino, Italy \\ ${ }^{2}$ Dipartimento di Fisica Sperimentale, Università di Torino, Italy
}

\begin{abstract}
We present an overview of the radon surveys at Stromboli island starting from the 2002, with the aim to better understand the relation between in-soil radon degassing and change in volcanic activity. Radon measurements were performed by means of different, passive, methodologies. By using a radon network of 21 sampling sites, placed in the $\mathrm{NE}$ sector of the island, we effected periodic surveys by means of two manually techniques. Track-etch detectors and EPERM electrets allowed us to construct a continuous time-series of radon measurements during the period 2002-2007 and to recognize the short-time variations. Radon activity shows, by means of EPERM ${ }^{\circledR}$ electrets, a wide range of values, from 0.3 to $50 \mathrm{kBq} / \mathrm{m}^{3}$. These data confirm the role of the local effects on the in-soil radon emissions and show that the structural alignments represent a preferential pathways for the radon migration from soil to air. From the 2007 we developed two real-time multiparametric, fully automated stations where the measurements of radon activity, acquired every 15 minutes, are correlated with the soil temperature and atmospheric pressure data. The first results show the important role of the atmospheric factors (e.g. soil temperature) in the acquired radon measurements.
\end{abstract}

\section{Introduction}

$\mathrm{Rn}-222$ (in the following referred to as radon) is a radioactive noble gas generated from the decay of ${ }^{226} \mathrm{Ra}$, and belongs to the ${ }^{238} \mathrm{U}$ decay chain.

This is an Open Access article distributed under the terms of the Creative Commons Attribution License 2.0, which permits unrestricted use, distribution, and reproduction in any medium, provided the original work is properly cited. 
Radon measurements and their transport processes are largely employed and investigated because of their relevance in health physics and, also, in the geophysical field. Radon transport towards the surface occurs preferentially along faults or cracks of the substrate; it is ruled by the physical parameters of the lithological units (porosity and permeability) and by the occurrence and the extension of the hydrothermal system. Due to its very low concentration in magma, radon transport to the surface occurs via water vapour and gas phases (i.e. $\mathrm{CO}_{2}, \mathrm{SO}_{2}$ ). Due to its short half-life (3.82 days) radon is a useful tracer of the processes occurring in the upper part of the earth crust.

Radon measurements can be helpful in several geological context (e.g. mines, geothermal area) and its continuous monitoring represents an important tool in order to track precursors in large sector of the natural risk mitigation. From this point of view, radon monitoring coupled with the measurement of atmospheric properties shows the major influence of the environmental parameters on the capability of radon to move towards the surface.

Here, we present a brief overview on the in-soil radon surveys performed at Stromboli island by our research group, starting from May 2002 using different methodologies.

\section{Methodologies and measurements}

In May 2002 we deployed a network of radon sampling sites, at Stromboli island (cf. fig. 1a). In the entire network, periodic measurements are done using two passive techniques of in-soil radon detection, track-etch detectors and electrets. Both detectors were placed in subsurface pipe-like samplers ( $1.20 \mathrm{~m}$ long, with a diameter of $12 \mathrm{~cm}$ ), which were set to a depth of about $60 \mathrm{~cm}$, and isolated by a cap to minimise condensation. The track-etch detectors (LR115 films, calibrated according to [1]), exposed for two to five weeks; allowed us to build a continuous time-series of radon activity able to evidence the long-time variations. On the other hand, periodic surveys effected by means of E-PERM ${ }^{\circledR}$ electrets [2] that was exposed for one to four days, gave us the opportunity to detect short-time variations. These detectors were collected manually and read out in laboratory giving integrated measurements of radon activity during their time of exposure. After the 2007 effusive episode of the Stromboli volcano, we selected two sites for the installation of the multiparametric ${ }^{222} \mathrm{Rn}$ real-time monitoring station; where radon measurements are coupled with the acquisition of soil temperature and atmospheric pressure. 


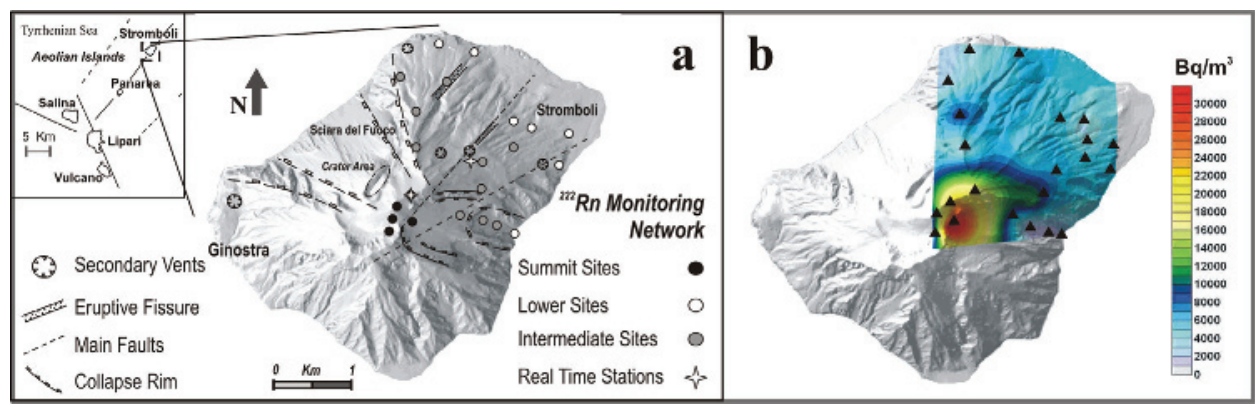

Figure 1: a) Location of the Stromboli volcano in the Southern Tyrrhenian Sea. The main structural features of the island are shown on the topographic DEM. The radon network is divided related to the distance from the active vents. b) The average radon activity on the referred sampling sites obtained by the EPERM ${ }^{\circledR}$ measurements during the period 2002-2007.

The real-time stations for continuous radon monitoring are made of the electronic radon dosimeter DOSEman (produced by Sarad GmbH, Dresden, Germany), integrated with an electronic board that transfers the output signal to a modem. The sampling time for radon (and related progeny) and environmental parameters is 15 minutes. The acquired data are instantaneously elaborated and plotted on a monitor that can be remotely checked. The DOSEman detects alpha-particle decays within an energy window ranging from 4500 to $10000 \mathrm{keV}$ that includes the peaks of ${ }^{222} \mathrm{Rn}$ itself $(5590.3 \mathrm{keV})$, plus the peaks of the daughter products $\left({ }^{218} \mathrm{Po}\right.$ and ${ }^{214} \mathrm{Po}$; at 6114.68 and $7833.46 \mathrm{keV}$, respectively) as well as the energy interval represented by ${ }^{220} \mathrm{Rn}$ (thoron, a radon isotope due to the decay of the ${ }^{232} \mathrm{Th}$ chain). The radon concentration is calculated, using appropriate calibration factors, either by taking into account the counts regarding only the ${ }^{218} \mathrm{Po}$ peak area, or by the combined use of the ${ }^{218} \mathrm{Po}$ and ${ }^{214} \mathrm{Po}$ peaks [3].

\section{Radon data results}

This survey on a large sector of the island demonstrates the occurrence of diffuse degassing at Stromboli; it is worth noting that higher ${ }^{222} \mathrm{Rn}$ emissions are related to the main structural alignments and to the proximity of the crater area. The large dataset acquired using EPERM ${ }^{\circledR}$ electret (2300 data points) has been analysed statistically (see $[4,5]$ ), in order to characterise the background, and the threshold and to determine anomalous values at each measurement site. In order to give a clearer view of the radon concentration values, we divided the 21 sampling sites in three distinct groups, in relation 


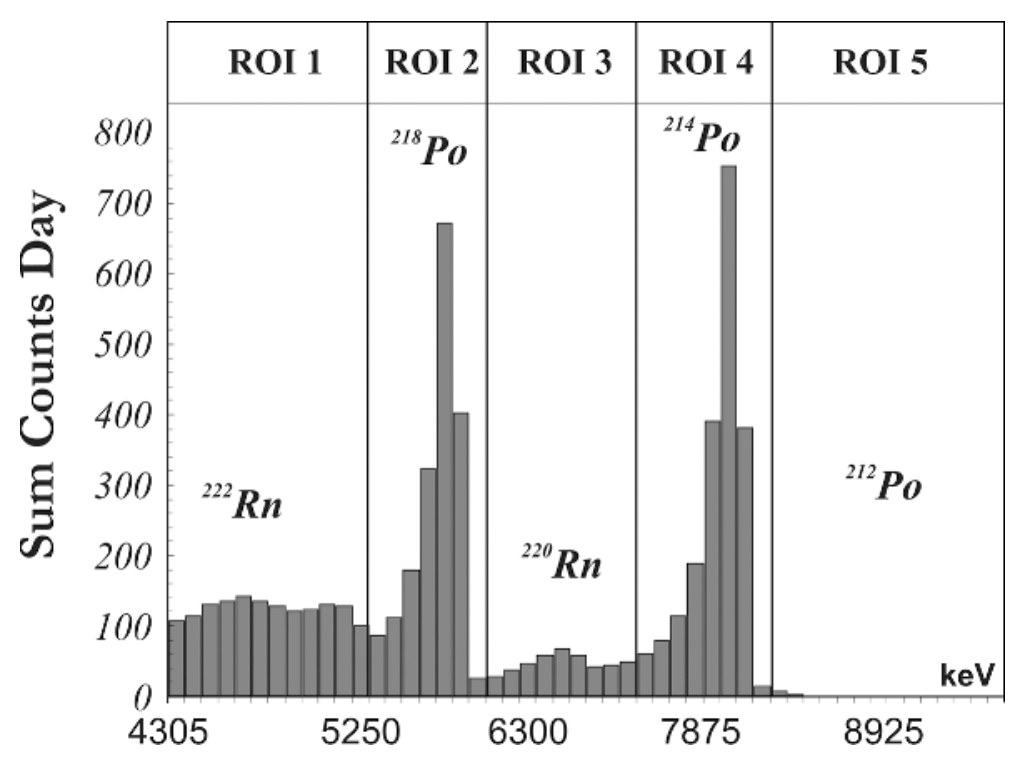

Figure 2: Distribution of the alpha-decay measurements obtained at the summit real-time station (PZZ) with the DOSEMan radonmeter starting from April 2007.

to their distance from the crater area (Figure 1a). However, considering the entire network, the activity values are ranging (in space and in time) from 0.3 to $30 \mathrm{kBq} \mathrm{m}^{-3}$. The measurements confirm the relation between volcanic activity and in-soil ${ }^{222} \mathrm{Rn}$ activity; in fact, the highest concentrations, measured at several sites of the network, were recorded during the two effusive events of the Stromboli volcano [6].

Moreover, as previously cited, the average radon concentration at each site shows in general an inverse relationship with the distance from the active vents (fig. 1b, cf. [7]). But, stations placed at similar distances from the craters measure different radon concentrations, outlining the presence of local effects during the radon discharge. This behaviour is evidenced in the spatial distribution of the average radon activity on the topographic DEM (Digital Elevation Model) of the Stromboli volcanic structure.

The two sites (cf. fig. 1) of the real-time measurements show different average values (fig. 3) confirming that close to the summit area and to the fracture diffuse radon degassing is efficient. The radon activity at summit station (PZZ, located near to the crater area; cf. fig. 1) is $11 \mathrm{kBq} \mathrm{m}^{-3}$ (with a standard deviation of $4 \mathrm{kBq} \mathrm{m}^{-3}$ ), while at the other site (LSC, placed far from the crater vents; cf. fig. 1) the average radon concentration is of the order of $1.8 \mathrm{kBq} \mathrm{m}^{-3}$, with a high SD $\left(\sim 0.9 \mathrm{kBq} \mathrm{m}^{-3}\right)$. The automated mea- 

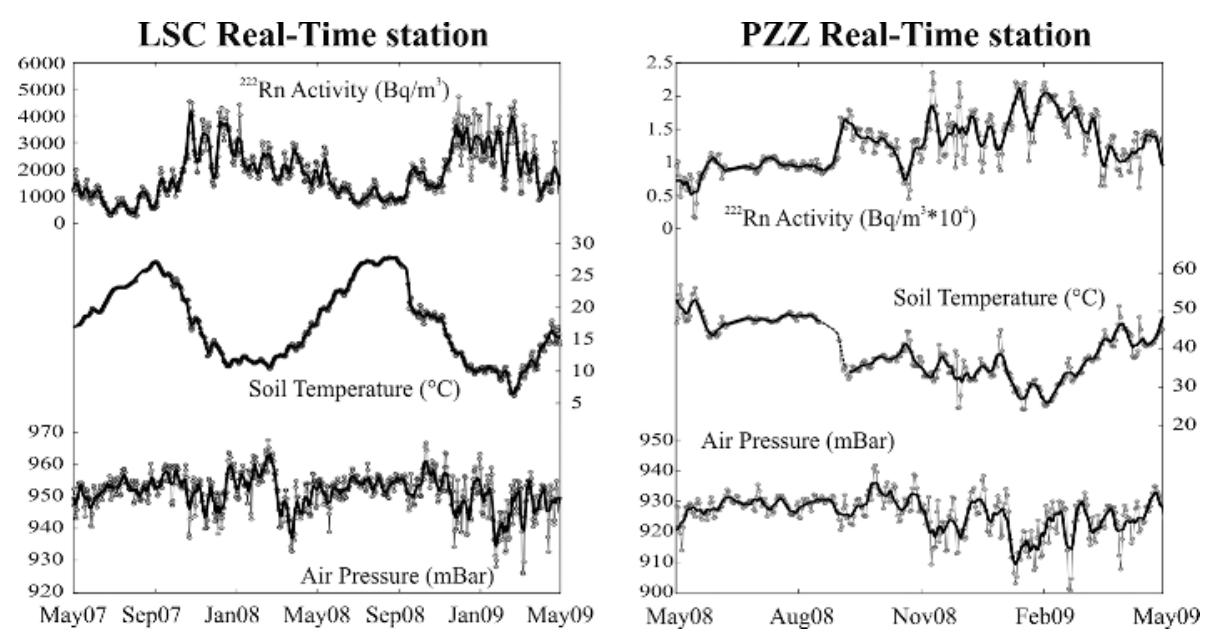

Figure 3: Time-series of the first years of real-time radon monitoring with the two distinct fully-automated stations at the Stromboli volcano.

surements show, as a first result, the clear inverse relationship between the radon activity and the soil temperature (correlation coefficient close to 0.8) reflecting that shallow degassing is the principle component at these sites, where the thermal gradient at the soil-air interface is the most important process to modulate the radon transport towards the surface. It is worth noting that only a weak inverse correlation $(-0.31$ and -0.35 for the two measurement sites, respectively) is observed between the radon concentration and the atmospheric pressure [6].

\section{Conclusions}

Periodic surveys and real-time radon monitoring indicate that the in-soil radon activity is sensible to the observed variations in volcanic activity as well as to the variation of environmental parameters. The spatial distribution of the radon activity, determined via a radon monitoring network, supports the idea that diffuse degassing at the Stromboli volcano is mainly following its structural framework and determined also by the distance to the active crater area. Finally, real-time measurements performed at two distinct sites show that the radon activity and, hence, the radon transport to the surface, is influenced by changes in the environmental conditions, especially by changes in the soil temperature. 


\section{References}

[1] Bonetti R., Capra L., Chiesa C., Guglielmetti A. and Migliorini C., Nucl. Rad. Measur., 18 (1991) 321-338.

[2] Kotrappa P., Dempsey J.C. and Stieff L.R., Rad. Prot. Dosim., 47 (1993) 461-464.

[3] Gründel M. and Postendörfer J., Rad, Protect. Dosim., 107-4 (2003) 287-292.

[4] Sinclair A.J., J. Geochem. Explor., 3 (1974) 1929-149.

[5] Carapezza M.L., Ricci T., Ranaldi M. and Tarchini L., J. Volcanol. Geotherm. Res., 182 (2009) 231-245.

[6] Cigolini C., Poggi P., Ripepe M., Laiolo M., Ciamberlini C., Delle Donne D., Ulivieri G., Coppola D., Lacanna G., Marchetti E., Piscopo D. and Genco R., J. Volcanol. Geotherm. Res., 184 (2009) 381-388.

[7] Gervino G., Cigolini C., Lavagno A., Marino C., Prati P., Pruiti L. and Zangari G., Physica A, 340 (2004) 402-409. 